\title{
ESTADO DO CONHECIMENTO SOBRE FINANCIAMENTO DA EDUCAÇÃO OBRIGATÓRIA E PRIVATIZAÇÃO A PARTIR DO WEB OF SCIENCE, 2015-2018
}

\author{
ESTADO DEL CONOCIMIENTO ACERCA DE LA FINANCIACIÓN DE LA \\ EDUCACIÓN OBLIGATORIA Y LA PRIVATIZACIÓN EM LA WEB OF SCIENCE, \\ 2015-2018
}

\section{STATE OF KNOWLEDGE ABOUT FINANCING OF COMPULSORY EDUCATION AND PRIVATIZATION FROM WEB OF SCIENCE, 2015-2018}

RESUMO: Trata-se de um estado do conhecimento, Romanowski e Ens (2006), construído a partir de levantamento de publicações entre 2015-2018 em periódicos que integram a Web of Science. O inventário foi realizado pelo descritor Financing identificado em títulos, resumos e palavras-chave em trabalhos circunscritos à educação básica/obrigatória. A análise dos resumos indicou que $23 \%$, dos 76 artigos selecionados, abordaram o tema da privatização, a maioria por autores estadunidenses. A produção brasileira foi a terceira mais frequente, embora sem análises sobre formas de privatização. O estudo indicou ainda que escolha parental foi a forma de privatização mais analisada.

PALAVRAS-CHAVE: Estado do conhecimento. Financiamento. Privatização. Educação obrigatória.

RESUMEN: Es un estado de conocimiento, Romanowski y Ens (2006), construído a partir de busca entre 2015-2018 en periódicos de la Web of Science. El inventario fue realizado por el descriptor Financing en títulos, resúmenes y palabras clave y circunscrito a educación básica/obligatoria. El análisis de los resúmenes indicó que 23\%, de los 76 artículos seleccionados, abordó el tema de la privatización, más por autores americanos. La producción brasileña fue la tercera más frecuente, aunque no examinó las formas de privatización. El estudio encontró que los mecanismos de elección de los padres todavía era la forma de privatización (Adrião, 2018).

PALABRAS CLAVE: Estado del conocimiento. Financiamiento. Privatización. Educación obligatoria.

ABSTRACT: It is a state of knowledge, Romanowski and Ens (2006), constructed from gathering, between 2015 and 2018, of publications on periodicals that compose the Web of

1 Universidade Estadual de Campinas (Unicamp), Campinas - SP - Brasil. Graduando em Licenciatura em Pedagogia. ORCID: <http://orcid.org/0000-0002-7314-254X>. E-mail: andrey.mori@gmail.com 2 Universidade Estadual de Campinas (Unicamp), Campinas - SP - Brasil. Professora Livre-Docente do Departamento de Política, Administração e Sistemas Educacionais. ORCID: <http://orcid.org/0000-0003-11815873>. E-mail: theadriao@gmail.com 
Science. The inventory was realised by the Financing descriptor identified on titles, abstracts and key-words on works circunscript to basic/compulsory education. the analysis of the abstracts indicated that $23 \%$ of the 76 selected articles approached the privatization theme, the majority by north-american authors. The brazilian production was the third most frequent, although without analysis of the privatization's means. The study also indicated that parental choice was the most analyzed mean of privatization (Adrião, 2018).

KEYWORDS: State of knowledge. Financing. Privatization. Compulsory education.

\section{Introdução}

O presente trabalho, articulado a projeto de pesquisa financiado pelo CNPq e Fapesp, tem como objetivo identificar e caracterizar as produções em periódicos de língua inglesa relativas ao financiamento da educação no âmbito da educação básica ou equivalente, no período 2015-2018. O período previsto para este inventário dá continuidade à pesquisa anterior (ADRIÃO, 2015).

Trata-se de uma análise bibliométrica, entendida como uma "técnica quantitativa e estatística de medição dos índices de produção e disseminação do conhecimento científico" (ARAÚJO, 2006, p. 12), que surge a partir da necessidade de estudar e avaliar as produções e as comunicações da comunidade científica. Não se trata de um limitante matemático, "racional", "objetivo" ou "isento de valor" da produção, tampouco de um ranqueamento das universidades, pesquisadores, revistas ou países; trata-se, na verdade, da primeira etapa da produção de conhecimento, através da qual se constata a produção prévia, organiza-a e identifica suas tendências e lacunas. É importante na medida em que facilita o planejamento de pesquisas futuras.

De acordo com as Romanowski e Ens (2006), o trabalho se enquadra em inventário de tipo estado do conhecimento, na medida em que aborda uma parcela das publicações sobre determinado tema, Na mesma direção, Nogueira (2015) afirma que estado da arte "abrange a produção de conhecimento em uma determinada área, focalizando os diversos tipos de publicações disponíveis", enquanto que o estado do conhecimento "aborda um único setor das publicações sobre um tema" (NOGUEIRA, 2015, p. 1), neste artigo o setor restringe-se aos artigos em periódicos disponíveis no Web of Science. Trata-se, pois, de um estudo exploratório, de caráter documental, bibliográfico e descritivo.

Antecipando parte da metodologia, este estado do conhecimento restringiu-se a artigos em periódicos internacionais e teve como único descritor "financing", tendo em vista que o objetivo foi a elaboração de um balanço sistematizado do que foi produzido e publicado em 
período recente. $\mathrm{O}$ artigo apresenta informações sobre as abordagens metodológicas dos trabalhos, os centros de investigação e os periódicos que mais publicaram sobre o tema, os países de origem dos autores e o campo empírico analisado, auxiliando na problematização da temática entre nós e na apreensão da amplitude do que já foi e vem sendo produzido.

Considerou-se ainda, em acordo com Ferreira (2002), as informações presentes nos resumos dos artigos selecionados, tendo em vista ser este elemento pré-textual, fonte de informação sobre os aspectos considerados neste inventário.

Optou-se por apresentar os resultados em duas dimensões. A primeira é quantitativa, na qual se identificou: 1 . as revistas que mais recorrentemente publicaram sobre o tema no período elegido; 2. as instituições sede dos autores que publicaram sobre o tema no período selecionado e o tipo de instituição das quais derivam os textos; 3. os países sedes das instituições com autores que publicaram sobre o tema. A segunda dimensão é quali-quantitativa, na qual se buscou, por meio da leitura dos resumos, identificar: 1. a etapa de escolaridade considerada nos artigos; 2. o campo empírico (país) analisado na publicação; 3. o tipo de abordagem metodológica utilizada no artigo apresentada nos resumos; 4. se o trabalho aborda a privatização da educação.

\section{Metodologia}

O levantamento dos artigos teve como base de dados a Principal Coleção do Web of Science (Web of Science - Coleção Principal - Clarivate Analytics), do Web of Science [v.5.30] $]^{3}$, acessada pelo site da Capes, a partir de VPN obtido do Centro de Computação da Unicamp (CCUEC). Esta base de dados é multidisciplinar e "indexa somente os periódicos mais citados em suas respectivas áreas", informando, para cada artigo, "os documentos por ele citados e os documentos que o citaram", e, para isso, conta com mais de 9.000 periódicos indexados. ${ }^{4}$

A escolha do intervalo 2015-2018 levou em conta o diálogo com o trabalho de Adrião (2015) que, em estado da arte, inventariou produções sobre privatização da educação entre 1990-2015, a partir de sete descritores, dentre os quais financing.

3Disponível em: http://apps-webofknowledge.ez88.periodicos.capes.gov.br/WOS_GeneralSearch_input.do? product=WOS\&search_mode=GeneralSearch $\&$ SID=8DWRD6FaCGYddvpryo6\&preferencesSaved $=. \quad$ Acesso em: 14 set. 2018.

4Para mais informações sobre o Web of Science, ver em: http://buscador-periodicos-capes-govbr.ez88.periodicos.capes.gov.br/V/A75V7YB7HLDC6JJM6YM6KVB9AN8MPV1KN7I18DLUYXNEVBLTL U-02241?func=find-db-info\&doc_num=000002653. Acesso em: 14 set. 2018. 
A coleta foi concluída em setembro de 2018, de modo que os artigos publicados a partir deste mês não integram este levantamento. O percurso metodológico para a identificação dos artigos considerou: o acesso à plataforma do Web of Science (WoS), o descritor "financing" pesquisado como "Tópico", isto é, abarcando todas as publicações que mencionassem "financing" em seu título, resumo, palavras-chave ou afins. Estipulou-se quatro intervalos de anos personalizados: 2015-2015, 2016-2016, 2017-2017 e 2018-2018.

Os resultados, inicialmente, obtidos foram por demais amplos (total de 27.261 artigos, entre 2015 e 2018) já que eram exibidas todas as publicações com menção a "financing", independente da área de estudo e pesquisa. Exigiu-se, portanto, algumas filtragens.

A primeira filtragem se deu pela escolha do "Education Educational Research" na "Web of Science Categories" acessado de tal modo que as publicações ficaram restritas ao campo da Educação. Em seguida, escolheu-se o tipo de documento ("Document Types"), restringindo-se, neste caso, às produções na forma de artigo (acesso "Article").

Os resultados após estes processos de clivagem estão expressos na Tabela 1 a seguir:

Tabela 1 - Quantidade de resultados encontrados após primeira e segunda filtragens, por ano de publicação, na base Web of Science

\begin{tabular}{cccc}
\hline Ano & Pesquisa "Financing" & Primeira filtragem & Segunda filtragem \\
\hline 2015 & 6.891 & 301 & 108 \\
2016 & 7.424 & 394 & 145 \\
2017 & 7.721 & 315 & 141 \\
2018 & 5.225 & 108 & 99 \\
Total & $\mathbf{2 7 . 2 6 1}$ & $\mathbf{1 . 1 1 8}$ & $\mathbf{4 9 3}$ \\
\hline
\end{tabular}

Fonte: Elaboração própria

Após a leitura dos resumos e títulos, excluem-se, destes 493 artigos encontrados, os que tratavam de ensino superior, educação financeira ou de educação não obrigatória, dado que o foco deste levantamento são produções sobre financiamento da e na educação regular obrigatória. De modo que neste processo, efetuou-se uma terceira etapa de "filtragem", com vistas a selecionar somente os textos relativos a esta etapa de escolaridade.

Esta filtragem foi a última etapa antes da análise dos resumos das publicações. É importante dizer, ainda, que os trabalhos com resumo indisponível foram descartados, já que o levantamento aqui realizado se pautava no conteúdo desta parte dos artigos. O resultado encontra-se na tabela 2: 
Tabela 2 - Quantidade de artigos encontrados/selecionados após leitura dos resumos, por ano de publicação, na base Web of Science

\begin{tabular}{cc}
\hline Ano & Terceira filtragem \\
\hline 2015 & 14 \\
2016 & 26 \\
2017 & 21 \\
2018 & 15 \\
Total & $\mathbf{7 6}$ \\
\hline
\end{tabular}

Fonte: Elaboração própria (2018)

Convém dizer que, destes 76 artigos encontrados entre 2015 e 2018 sobre financiamento da educação na etapa regular, em 14 não foi possível acesso à publicação na íntegra.

\section{Onde, quando e por quem?}

Considerando o indicado na introdução deste trabalho as informações decorrentes do levantamento aqui realizado apresentam uma dimensão quantitativa e uma quali-quantitativa. A primeira expressa em três aspectos e a segunda em quatro aspectos.

Foram identificados diferentes 43 periódicos publicando artigos sobre financiamento na/da educação obrigatória, o que sugere que as publicações não estão concentradas em poucas revistas. De toda maneira, o periódico com maior número de artigos publicados é o Journal of Education Finance seguido pelo International Journal of Education Development. No conjunto temos 13 periódicos que publicaram dois ou mais artigos selecionados, sendo responsáveis por pouco mais de $60 \%$ do total de publicações entre 2015 e 2018, conforme tabela 3 . 
Tabela 3 - Quantidade de artigos nos 12 periódicos com dois ou mais artigos selecionados 2015-2018, Web of Science ${ }^{5}$

\begin{tabular}{cc}
\hline Periódico & Quantidade de publicações \\
\hline JOURNAL OF EDUCATION FINANCE & 13 \\
INTERNATIONAL JOURNAL OF EDUCATIONAL & 6 \\
DEVELOPMENT & 3 \\
EDUCATIONAL RESEARCHER & 3 \\
COMPARE-A JOURNAL OF COMPARATIVE AND & \\
INTERNATIONAL EDUCATION & 3 \\
ECONOMICS OF EDUCATION REVIEW & 3 \\
PAEDAGOGICA HISTORICA & 3 \\
SOUTH AFRICAN JOURNAL OF EDUCATION & 2 \\
COMPARATIVE EDUCATION & 2 \\
EDUCATION AND URBAN SOCIETY & 2 \\
LEACATIONAL MANAGEMENT ADMINISTRATION \& & 2 \\
EDUCATIONAL POLICY & 2 \\
LEADERSHIP AND POLICY IN SCHOOLS & 2 \\
JOURNAL OF EDUCATION POLICY &
\end{tabular}

Fonte: Elaboração própria

Entre as instituições às quais os autores estão vinculados, encontrou-se publicações que fazem referência a 87 instituições de ensino superior, 5 órgãos governamentais e 14 instituições não governamentais (diversas fundações e associações, mas também o Banco Mundial e a ActionAid). À exceção da ActionAid, com dois autores a ela associados, somente as instituições de ensino superior possuem mais de um autor a ela vinculados com destaque para a Universidade de Maryland, com 7 autores. Quatro universidades possuem quatro autores e nove universidades possuem três. Além disso, 16 universidades possuem dois autores associados. A tabela 4 indica as instituições com três ou mais autores associados publicando no período.

Tabela 4 - Quantidade de autores vinculados às doze instituições com três ou mais autores a ela associados, 2015-2018-WoS

5 Em função da grande quantidade de periódicos e considerando o limite de páginas deste artigo optou-se por restringir os periódicos aos que têm duas ou mais publicações no período. 


\begin{tabular}{cc}
\hline Instituição & Quantidade de autores \\
\hline Univ Maryland & 7 \\
Michigan State Univ & 4 \\
Univ Illinois & 4 \\
Univ Pretoria & 4 \\
Univ Fed Paraná & 4 \\
Univ British Columbia & 3 \\
Univ Estadual Maringá & 3 \\
Univ Manchester & 3 \\
Univ Amsterdam & 3 \\
Univ Oregon & 3 \\
Univ Montana & 3 \\
Univ KwaZulu Natal & 3 \\
Univ Guayaquil & 3 \\
Univ Autonoma Barcelona & 3 \\
\hline Ans & 3 \\
\hline
\end{tabular}

Fonte: Elaboração própria

Estas 14 universidades concentram 50 autores num universo de 148 autores, pouco mais de um terço $(33,8 \%)$. Não é demais dizer que quantidade de autores não equivale à quantidade de artigos, ou seja, um artigo pode ter dois autores diferentes na mesma Universidade, o que não faz desta informação menos relevante.

Entre os países que se destacam na publicação do tema, Estados Unidos se sobressai. Este país concentra 47,3\% dos autores que trataram do tema, o que, em números absolutos, são 70 autores dentre 148 totais. Em seguida, 12 pesquisadores estão vinculados a instituições brasileiras $(8,1 \%), 10$ a inglesas $(6,8 \%)$ e nove a sul africanas $(6,1 \%)$. Considerando as publicações, 47,4\% (36 artigos em 76) tinham autores associados aos EUA; depois, Brasil, África do Sul e Inglaterra com autores localizados em 6 artigos (7,9\%). As tabelas 5 e 6 apresentam mais informações a respeito.

Tabela 5 - Quantidade de autores associados a instituições por país, 2015-2018 - WoS 


\begin{tabular}{cc}
\hline País & Quantidade \\
\hline Estados Unidos & 70 \\
Brasil & 12 \\
Inglaterra & 10 \\
África do Sul & 9 \\
Holanda & 6 \\
Canadá & 5 \\
\hline
\end{tabular}

Fonte: Elaboração própria

Tabela 6 - Quantidade de publicações com pelo menos um autor associado ao país por país, 2015-2018, WoS

\begin{tabular}{cc}
\hline País & Quantidade \\
\hline Estados Unidos & 36 \\
Brasil & 6 \\
África do Sul & 6 \\
Inglaterra & 6 \\
Canadá & 4 \\
Holanda & 4 \\
\hline
\end{tabular}

Fonte: Elaboração própria

A tabela 5 restringiu-se aos países que possuem cinco ou mais autores, enquanto a tabela 6 aos que possuem quatro ou mais publicações. ${ }^{6}$ Coincidentemente, ficaram os mesmos países em ambas as tabelas. Isto expressa a concentração das publicações em poucos países: seis países (de 27 localizados) concentram 112 autores (dos 148 encontrados) que participam de 62 artigos (dos 76 selecionados).

Em relação ao campo empírico considerado nos textos, dos 76 artigos, 33 têm os Estados Unidos como campo empírico (43,4\%), 13 têm países europeus (17,1\%), 11 países asiáticos (14,5\%), 10 países africanos (13,2\%, sendo 6 artigos sobre África do Sul) e 8 países latinoamericanos (10,5\%), dos quais 5 abordam Brasil. Esta contabilização considerou que um mesmo artigo pode analisar mais de um campo empírico, por exemplo um artigo que compara 
a política de financiamento da educação em Oklahoma, Inglaterra e Israel foi considerado na contagem dos Estados Unidos, Europa e Ásia. Destaca-se que o artigo cujo campo empírico é a Turquia foi contabilizado tanto na Europa quanto na Ásia, dada a peculiaridade da situação geopolítica deste país. Em cinco artigos a noção de campo empírico não se aplicava.

Gráfico 1 - Quantidade de países que são campo empírico dos artigos identificados, 20152018, WoS

40

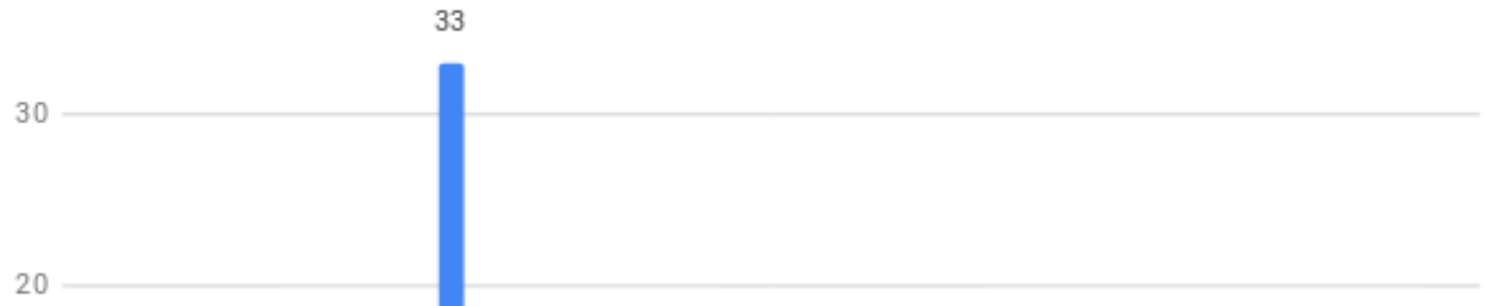

20

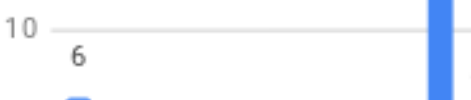

5

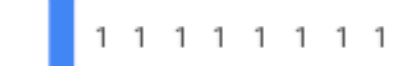

$\begin{array}{llllllllllllllllllllllllll}2 & 2 & 1 & 1 & 1 & & 2 & 2 & 1 & 2 & 1 & & 1 & 1 & 1 & 1 & 1 & 1 & 1 & 1 & 1 & 1 & 1\end{array}$

0

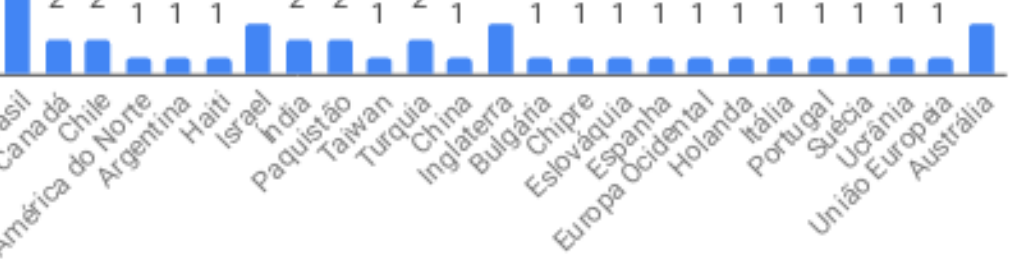

Fonte: Elaboração própria

Na sistematização da abordagem metodológica dos artigos, entende-se, como Gerhardt e Figueira (2009), que os trabalhos podem ser de cunho quantitativo ou quantitativo. Neste aspecto, 56 trabalhos indicavam nos resumos, explicitamente, a abordagem adotada, quase três quartos do total de artigos. A tabela 8 indica a distribuição dos artigos entre as abordagens qualitativas, quantitativas ou não identificados.

Tabela 8 - Distribuição dos artigos por abordagem metodológica a partir de seus resumos, 2015-2018, WoS

\begin{tabular}{ccc}
\hline Qualitativo & Quantitativo & Não identificado \\
\hline 32 & 24 & 20
\end{tabular}

Fonte: Elaboração própria 
Entre os elementos que permitiram identificar a abordagem, considerou-se, no caso das pesquisas qualitativas, menções a procedimentos metodológicos como entrevista semiestruturada, análise do discurso, análise documental, análise histórica e estudo de caso. Já no caso da menção explícita pela abordagem quantitativa, considerou-se para este enquadramento menções à regressão logística, modelos de efeitos fixos, função de custo, linha de base, grupo de controle e construção de indicadores, entre outros.

Por fim, identificou-se que $23,7 \%$ dos textos inventariados relacionam o estudo do financiamento explicitamente a temáticas da privatização, ou seja, dos 76 artigos, 18 tratam de privatização. Adrião $(2015,2018)$ caracteriza três dimensões de privatização da educação básica no período recente, são elas: da oferta, da gestão e do currículo.

Levando isto em conta, temos a distribuição dos artigos conforme tabela 9.

Tabela 9 - Quantidade de artigos por dimensão de privatização, 2015-2018, WoS

\begin{tabular}{ccc}
\hline Oferta & Gestão & Currículo \\
\hline 14 & 4 & 0
\end{tabular}

Fonte: Elaboração própria

A leitura dos resumos indica que nenhum artigo aborda mais de uma dimensão de privatização. De toda maneira, percebe-se que a maioria dos artigos se relacionam- à privatização da oferta. Por outro lado, a privatização do currículo não é identificada.

\section{Relação entre financiamento e privatização da educação nos artigos selecionados}

A partir de estudo desenvolvido por Adrião (2018), a literatura indica três dimensões da privatização da educação básica no período recente, cada uma com formas de privatização próprias. De acordo com a autora, são oito as formas de privatização da oferta educacional tratadas pela literatura. Considerando o financiamento público a organizações privadas, a autora enumera duas principais formas: o subsídio à oferta por meio de convênios/contratos entre governos e organizações privadas e o subsídio à demanda por meio de incentivos fiscais. Um segundo conjunto de formas de privatização da oferta pode ser percebido pela presença e ou ampliação de escolas particulares com fins de lucro, de tutorias e de aulas particulares. Um último conjunto envolve mecanismos de incentivo a políticas de escolha parental, mais precisamente, trata-se de sistemas em que o fundo público subsidia a escola particular em 
função do número de alunos matriculados, ou ainda pela adoção de sistemas de voucher, de créditos educativos ou da educação domiciliar.

Na segunda dimensão da educação - gestão da educação pública- a autora localizou cinco as formas de privatização. Considerando a privatização da gestão da escola, tem-se a transferência da gestão escolar para organizações com fins de lucro, sem fins de lucro ou ainda para cooperativas de trabalhadores e de pais. Já em âmbito sistêmico, a privatização da gestão educacional pública pode ser identificada por estudos que analisam a transferência da gestão do sistema educacional para organizações lucrativas, através de parcerias público-privadas (PPP) ou para organizações sem fins de lucro. (ADRIÃO, 2018)

Em relação à privatização do currículo, a terceira dimensão aqui considerada, identificou-se três formas de privatização: compra ou adoção, pelo poder público, de desenhos curriculares elaborados pelo setor privado, de tecnologias educacionais e demais insumos curriculares elaborados pelo setor privado, e, por último, através dos Sistemas Privados de Ensino. (ADRIÃO, 2018)

Levando em conta essa "tipificação", a tabela 10 sistematiza as formas consideradas nos $18 \operatorname{artigos}^{7}$ nos quais o tema da privatização da educação básica foi explícita ou implicitamente abordado.

Tabela 10 - Formas de Privatização da Oferta educacional e artigos que a analisam, 20152018, WoS

\begin{tabular}{ccc}
\hline $\begin{array}{c}\text { Formas de Privatização } \\
\text { da Oferta }\end{array}$ & $\begin{array}{c}\text { Número de } \\
\text { artigos }\end{array}$ & Autores e ano de publicação \\
\hline $\begin{array}{c}\text { Financiamento público a } \\
\text { organizações privadas }\end{array}$ & 5 & $\begin{array}{c}\text { Maussen; Bader, 2015. Dronkers; Avram, 2015. Kumari, } \\
\text { 2016. Theodorou; Pashiardis, 2016. Rivera, 2018. }\end{array}$ \\
Oferta privada & 4 & Poole; Fallon, 2015. Narodowski; Moschetti, 2015. \\
Kumari, 2016. Mitch, 2016.
\end{tabular}

Fonte: Elaboração própria

Considerando o total de resumos nos quais o tema de privatização foi identificado, percebe-se que a maioria analisa a privatização da oferta principalmente por meio de

7 Os artigos anunciados nas tabelas 10 e 12 não constam como referências bibliográficas deste artigo, visto que estas são limitadas. Optou-se ainda assim por anunciá-los. 
mecanismos de incentivo à escolha parental. Tal primazia associa-se, por sua vez, ao campo empírico analisado pelos textos apresentados na Tabela 11, na qual se destaca os Estados Unidos, país no qual o tema das escolas charter ou da introdução de vouchers ou da educação domiciliar tem se ampliado a partir da gestão de Donald Trump.

Tabela 11 - Campos empíricos de artigos que tratam de privatização da oferta, 2015-2018, WoS

\begin{tabular}{cc}
\hline Campo empírico & Quantidade \\
\hline Estados Unidos & 3 \\
Índia & 2 \\
Canadá & 1 \\
Argentina & 1 \\
Chile & 1 \\
África do Sul & 1 \\
Europa Ocidental & 1 \\
União Europeia & 1 \\
\hline
\end{tabular}

Fonte: Elaboração própria

Nota-se que dois artigos que tratam de privatização da oferta não se referem a um único país, mas a países da Europa Ocidental e a países da União Europeia.

Interessante observar que três artigos não analisam fenômenos ou situações atuais. Dois destes abordam o tema a presença do setor privado na oferta educacional do ponto de vista histórico, na Inglaterra do século XIX e Holanda nos séculos XVIII e XIX; o primeiro trata de fundos filantrópicos como conformadores da constituição do sistema nacional de ensino e o segundo da disputa dos fundos públicos por escolas confessionais. O terceiro artigo, um ensaio, reflete a respeito de como os pobres respondem ao mercado educacional decorrente da introdução de vouchers.

Em relação à privatização da gestão da educação, a tabela 12 anuncia que a maioria (3) abordam situações em que os sistemas educacionais estão privatizados.

Tabela 12 - Formas de privatização da gestão e artigos identificados, 2015-2018, WoS 


\begin{tabular}{ccc}
\hline Formas de privatização da gestão & $\begin{array}{c}\text { Número de } \\
\text { artigos }\end{array}$ & Autores e ano da publicação \\
\hline $\begin{array}{c}\text { Privatização da gestão escolar } \\
\begin{array}{c}\text { Privatização da gestão educacional } \\
\text { pública }\end{array}\end{array}$ & 1 & Mestry, 2016. \\
\hline
\end{tabular}

Fonte: Elaboração própria

Em relação ao campo empírico (tabela 13), tem-se um artigo que analisa distintos contextos: a atuação da Global Partnership for Education na Libéria, Madagascar e República Democrática do Congo.

Tabela 13 - Campos empíricos de artigos que tratam de privatização da gestão, 2015-2018, WoS

\begin{tabular}{cc}
\hline Campo empírico & Quantidade \\
\hline Libéria, Madagascar e República Democrática do Congo & 1 \\
Canadá & 1 \\
África do Sul & 1 \\
EUA & 1 \\
\hline
\end{tabular}

Fonte: Elaboração própria

\section{Considerações finais}

Considerando a natureza deste trabalho e as limitações decorrentes deste tipo de pesquisa, tendo em vista limitar-se à análise de resumos e sendo que estes nem sempre se apresentam de fato como um breviário do trabalho completo (WITTIMANN; GRACINDO, 2001; MARTINS, 2009), convém atentar para alguns dos achados já anunciados anteriormente, mas que se apresentam particularmente interessantes para a construção do campo da pesquisa sobre privatização e sua interface com o financiamento da educação.

O primeiro aspecto é confirmação da existência de correlação entre estudos sobre financiamento e privatização tendo em vista que $23 \%$ dos trabalhos apresentavam em seus resumos essa articulação. De modo que o descritor financiamento deve ser considerado para a busca de trabalhos sobre privatização.

Percebeu-se também que a frequência de publicações sobre o Brasil por pesquisadores brasileiros, ainda que numericamente inferior a estadunidense, é relevante tendo no período 
correspondido ao terceiro campo empírico mais estudado. Vale lembrar que a eleição de Donald Trump em 2016 colocou no centro do debate educacional americano, as políticas de escolha parental tendo em vista os compromissos assumidos em sua campanha, conjuntura que explica, ao menos em parte, a frequência com que o tema da privatização foi tratado para aquele campo empírico.

Por outro lado, nenhum dos artigos brasileiros tratou do tema da privatização, o que indica a pouca visibilidade internacional em periódicos que integram a Web of Science dos estudos desenvolvidos entre nós. Acerca desta "limitação brasileira", os gráficos 2 e 3 apresentam informações comparando anualmente os seis países com destaque já sinalizado neste levantamento. O gráfico 2 apresenta a quantidade de autores e o país de origem de sua instituição de filiação.

Gráfico 2 - Quantidade de autores associados a instituições por país, por ano, 2015-2018, WoS

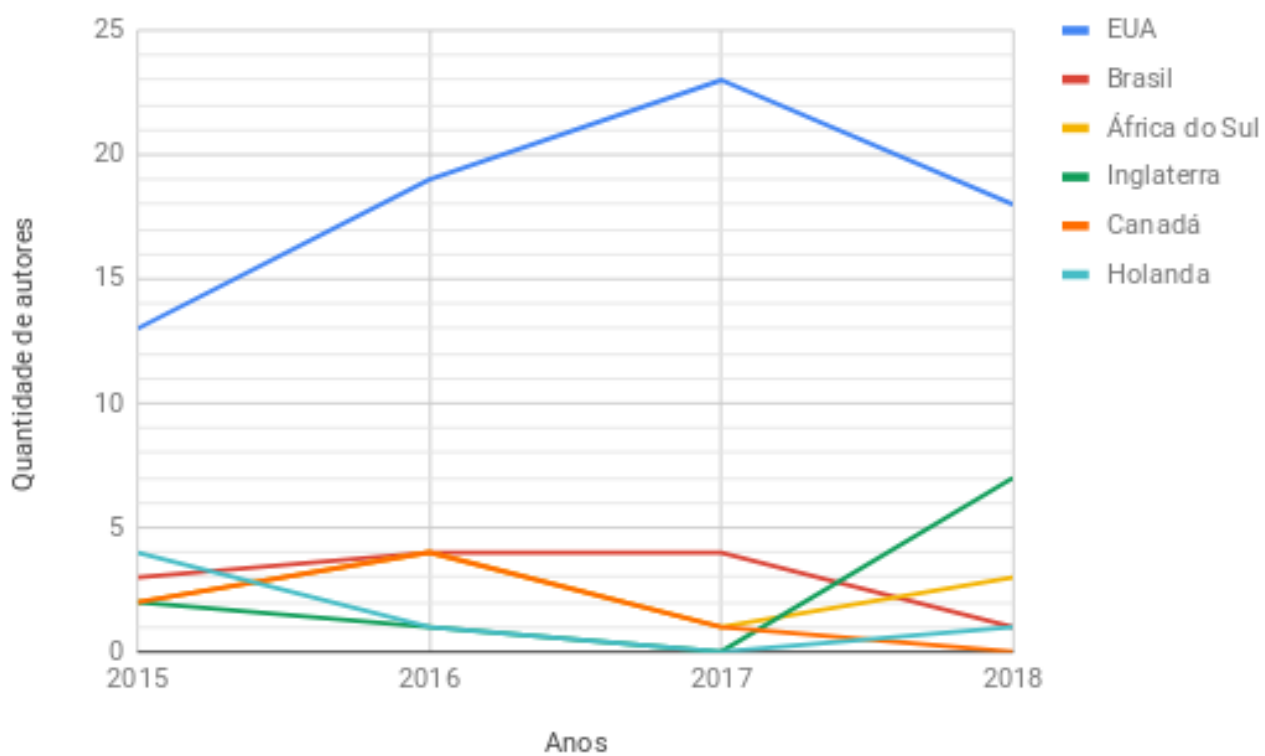

Fonte: Elaboração própria

O gráfico 3 apresenta o volume de artigos publicados por país. Este atrelamento foi feito a partir dos autores das publicações e suas respectivas associações a instituições sediadas no país.

Gráfico 3 - Quantidade de publicações por autores associados a instituições por país, por ano, 2015-2018, WoS 


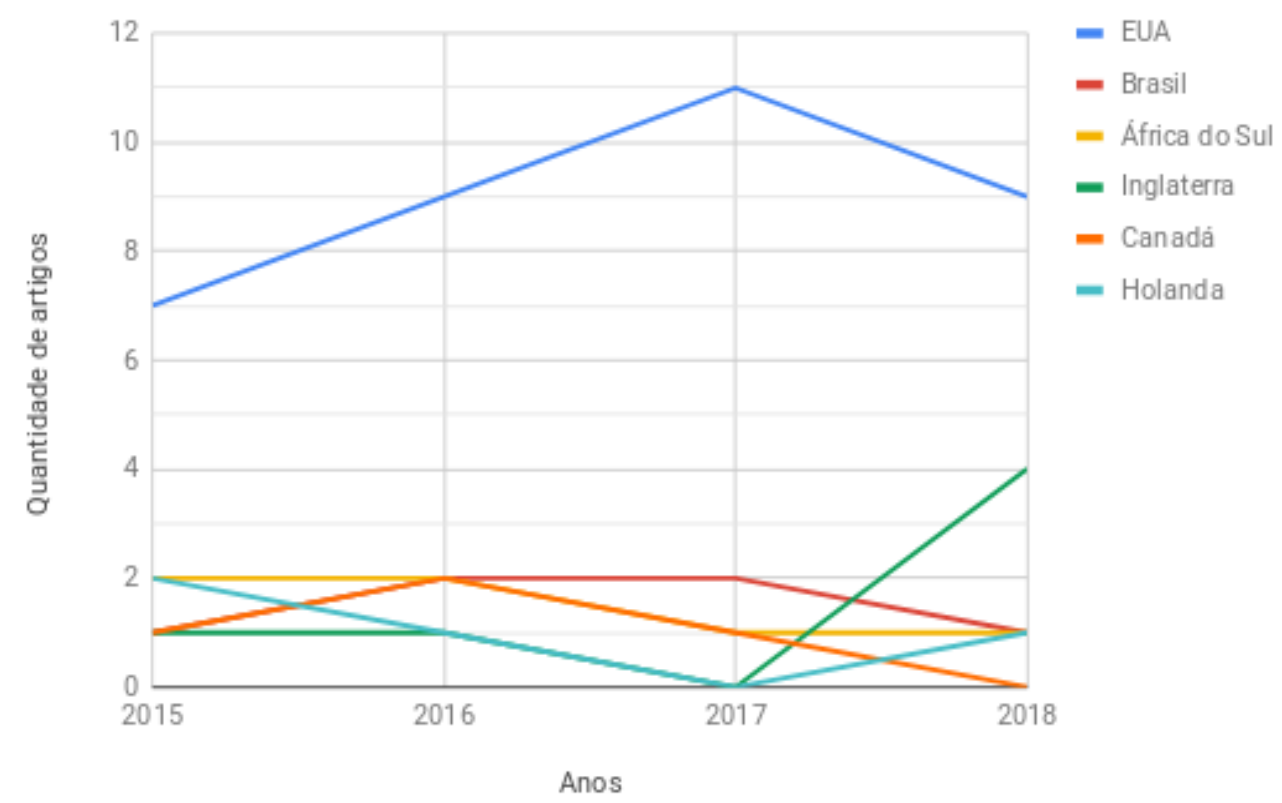

Fonte: Elaboração própria

Esta comparação evidencia a grande quantidade de publicações e de autores estadunidenses envolvidos na pesquisa em financiamento da educação, ao passo que outros países estão bem abaixo. Ademais, nota-se, no período analisado, uma tendência de aumento de publicações relacionadas ao financiamento da educação na etapa regular nos Estados Unidos; tendência não verificada para os outros países.

Tema a ser destacado refere-se ao volume maior de artigos sobre privatização da oferta educacional. Em que pese se tratar de formas mais recorrentes de privatização da educação (BELFIELD; LEVIN, 2002), a maior frequência de artigos que as analisam também ilustra os processos de intensificação e ampliação de mecanismos de escolha parental associados a orientações neoliberais e ou conservadoras em diversas regiões, confirmando tendência verificada para o período anterior por Adrião (2015). A privatização da gestão da educação foi tratada em mais artigos que a privatização da gestão da escola, e não se registrou estudos sobre privatização do currículo por esse descritor.

Por outro lado, chama a atenção a ausência de publicações localizadas pelo descritor financiamento que analisem aspectos de privatização dos currículos, especialmente porque tal dimensão tem sido sobremaneira explorada por corporações ou pelos filantrocapitalistas (DALE, 1996; BALL; YODELL, 2008; ROBERTSON, 2008; ADRIÃO, 2017).

Por fim, indica-se a necessidade de olhar com mais acuidade a estes achados dialogando com outras bases e trabalhos desta natureza. 


\section{REFERÊNCIAS}

ADRIÃO, T. Dimensões da privatização da educação básica no Brasil a partir de 1990: um diálogo com a produção acadêmica. 2015. 227f. Tese (Livre-Docência), Universidade Estadual de Campinas.

ADRIÃO, T. A privatização dos processos pedagógicos: Grupos editoriais e os negócios na educação básica. In: MARINGONI, G. (Org.). O negócio da educação. São Paulo: Olho D’água e Fepesp. p. 129-144, 2017.

ADRIÃO, T. Dimensões e formas da privatização da educação no Brasil: caracterização a partir de mapeamento de produções nacionais e internacionais. Currículo sem fronteiras, v. 18, n. 1, p. 8-28, jan./abr. 2018.

ARAÚJO, C. Bibliometria: evolução histórica e questões atuais. Em Questão, Porto Alegre, v. 12, n. 1, p. 11-32, jan./jun. 2006.

BALL, S.; YOUDELL, D. Hidden privatisation in public education. 2008. Disponível em: https://pages.ei-

ie.org/quadrennialreport/2007/upload/content_trsl_images/630/Hidden_privatisation-EN.pdf. Acesso em: 17 nov. 2018.

BELFIELD, C.; LEVIN, H. Education Privatization: Causes, Consequences, and Planning Implications. Paris, UNESCO-IIPE, 2002.

DALE, R. A promoção do mercado educacional e a polarização da educação. Educação, Sociedade e Cultura, n. 2, p. 109-139, 1996 Disponível em http://www.fpce.up.pt/ciie/revistaesc/ESC2/2-6-dale.pdf> Acesso em: 17 nov. 2018.

FERREIRA, N. S. A. As pesquisas denominadas "estado da arte". Educação \& Sociedade, Campinas, v. 23, n. 79, p. 257-272, ago. 2002. Disponível em:

http://www.scielo.br/scielo.php?script=sci_arttext\&pid=S010173302002000300013\&lng=en\&nrm=iso. Acesso em: 17 nov. 2018.

GERHARDT, T. E.; SILVEIRA, D. T. (Orgs.). Métodos de pesquisa. Porto Alegre: Editora da UFRGS, 2009.

MARTINS, A. (Org.). Estado da Arte: Gestão, autonomia escolar e órgãos colegiados. Brasília: Editora Liber Livro, 2011.

NOGUEIRA, M. A. Teses e dissertações sobre a relação família-escola no. Brasil (19972011): um estado do conhecimento. 37 ${ }^{\mathbf{a}}$ Reunião Anual da ANPEd, UFSC - Florianópolis, 2015. Disponível em: http://37reuniao.anped.org.br/wp-content/uploads/2015/02/TrabalhoGT14-4137.pdf. Acesso em: 17 nov. 2018.

ROBERTSON, S. L. Parcerias público-privadas, empresas digitais e a produção de um espaço educacional neoliberal em escala européia. Educ. Pesqui., São Paulo, v. 34, n. 3, p. 573-586, dez. 2008. 
ROMANOWSKI, J. P.; ENS, R. T. As pesquisas denominadas do tipo "estado da arte" em educação. Revista Diálogo Educacional, v. 6, n. 19, set./dez. 2006, p. 37-50.

WITTIMAN, L; GRACINDO, R. (Orgs.). Políticas e gestão da educação (1991-1997). Brasília: MEC/Inep/Comped, 2001.

\section{Como referenciar este artigo}

MORI, Andrey.; ADRIÃO, Theresa. Estado do conhecimento sobre financiamento da educação obrigatória e privatização a partir do Web of Science, 2015-2018. Revista on line de Política e Gestão Educacional, Araraquara, v. 22, n. esp. 3, p. 1241-1257, dez., 2018 ISSN: 1519-9029. DOI: $10.22633 /$ rpge.v0i0.12009

Submetido em: 10/10/2018

Aprovado em: 16/11/2018 